\title{
PAOLO BUDINI, Louise Labé poétesse lyonnaise. Essais, études, épreuves de lecture
}

\section{Maurizio Busca}

\section{OpenEdition}

\section{Journals}

\section{Edizione digitale}

URL: http://journals.openedition.org/studifrancesi/15054

DOI: 10.4000/studifrancesi. 15054

ISSN: 2427-5856

\section{Editore}

Rosenberg \& Sellier

\section{Edizione cartacea}

Data di pubblicazione: 1 décembre 2018

Paginazione: 487

ISSN: 0039-2944

\section{Notizia bibliografica digitale}

Maurizio Busca, «PAolo BuDINI, Louise Labé poétesse lyonnaise. Essais, études, épreuves de lecture», Studi Francesi [Online], 186 (LXII | III) | 2018, online dal 01 janvier 2019, consultato il 06 janvier 2021. URL: http://journals.openedition.org/studifrancesi/15054 ; DOI: https://doi.org/10.4000/studifrancesi. 15054

Questo documento è stato generato automaticamente il 6 janvier 2021.

\section{(c)}

Studi Francesi è distribuita con Licenza Creative Commons Attribuzione - Non commerciale - Non opere derivate 4.0 Internazionale. 


\title{
PAOLO BUDINI, Louise Labé poétesse lyonnaise. Essais, études, épreuves de lecture
}

\author{
Maurizio Busca
}

\section{NOTIZIA}

PAOLO BUDINI, Louise Labé poétesse lyonnaise. Essais, études, épreuves de lecture, Firenze, Leo

S. Olschki Editore, 2017, 184 pp.

1 L'editore Olschki riunisce in un unico volume dieci studi di Paolo Budini sull'opera di Louise Labé, oltre alla sua recensione del ben noto volume di Mireille Huchon su Labé e a un'appendice al secondo saggio edito in questa stessa raccolta. Si tratta di materiali in parte già pubblicati negli ultimi trent'anni in sedi diverse, materiali che l'A. definisce 'micro-analisi' o 'auscultazioni' (il termine è quanto mai appropriato, data la costante attenzione accordata agli aspetti fonetici) di testi della poetessa lionese: "Aufstieg und Fall" d'une icône du féminisme: Louise Labé, de la gloire des lettres à "puella scripta", pp. 9-27; Le sonnet italien de Louise Labé, pp. 31-43; Deux sonnets parallèles, pp. 45-66; Le sonnet aux oxymorons, pp.67-80; Deux thèmes: la nuit, la Mort, pp.81-93; Les sonnets du Luth, pp.95-107; Un vers ambigu, pp.109-119; Trois fables mythologiques: Zéphyr, Diane, l'harmonie céleste, pp.121-130; Le sonnet de la prédiction, pp. 131-143; Le dernier sonnet du "canzoniere", pp. 145-161.

2 Ai lavori già licenziati si affiancano diversi contributi originali. Le sonnet aux oxymorons propone una lettura parallela del sonetto VIII delle Euvres e dei sonetti CXXXII-CXXXIV di Petrarca, anche alla luce della lirica francese coeva (Scève, Pontus de Tyard, Du Bellay). Les sonnets $d u$ Luth affronta una lettura trasversale dei componimenti in cui compare lo strumento musicale prediletto dall'alta società del Cinquecento. È in particolare il sonetto centrale del canzoniere di Labé (XII) a suscitare le riflessioni dell'A., che ne analizza la struttura 'armonica' (il complesso gioco delle rime e degli 
echi interni) e 'melodica' (lo sviluppo del 'canto'). Ne Le sonnet de la prédiction, l'A. si interessa al componimento XX delle Euvres, di cui rileva dapprima i rapporti fra unità sintattiche e unità strofiche, quindi gli effetti prosodici e la 'struttura armonica verticale' (p. 136), per ritrovare infine tracce dei medesimi artifici stilistici nell'insieme del corpus della poetessa. In chiusura, Le dernier sonnet du canzoniere sottolinea i legami tematici che uniscono il sonetto XXIV ai componimenti precedenti, osservandone le peculiarità sintattico/strofiche che lo avvicinano ai sonetti XVII e XIX e la prossimità semantica col sonetto proemiale del Canzoniere petrarchesco. 